\title{
Study of the Correlation between Field Cognitive Styles and English Reading Strategies
}

\author{
Xinyu Lee \& Chao Wang \\ Foreign Language Department \\ Beijing Institute of Petrolchemical Technology \\ Beijing, China
}

\begin{abstract}
Cognitive style is an individual feature that can influence one's thinking, learning and problem-solving. Field cognitive style is the most accepted theory of all the classification of cognitive styles. With different field cognitive styles, readers tend to employ different reading strategies to understand and get information in reading, which is widely regarded as the most complicated cognitive process. Though many researchers have done similar researches, the present study focuses on students majoring in engineering at BIPT (Beijing Institute of Petrol-chemical Technology), who are adequately trained in mathematics and logic, and aims to find out whether they are more field dependent or field independent and whether there is a correlation between their field cognitive styles and preferences in reading strategy employment.
\end{abstract}

Ninety students were randomly chosen from the freshmen majoring in the material engineering at BIPT to participate in the study. They are all students with an English proficiency of level B (the intermediate level based on the Entrance Level Test hosted by BIPT). The Group Embedded Figure Test (Chinese version) is employed to test the participants' field cognitive style, and the reading strategy questionnaire is designed to find out the participants' preferences in reading strategy employment. The descriptive statistics, independent sample t-test and Pearson product moment correlation are obtained after processing data via SPSS 24.0.

The result of the study shows that there exists a certain tendency of field cognitive styles among freshmen majoring in material engineering at BIPT. A vast majority of them tend to be field independent. In addition, in this specific case, the field cognitive style does not have a significant correlation with the employment of English reading strategies. That means that the difference between students with FD and FI cognitive styles in using reading strategies is not as significant as that has been found out in previous studies. The study also reveals that FD learners are better at using social/affective reading strategies in reading.

Keywords: cognitive styles, English reading strategy, FD/FI styles

\section{Introduction}

Since 1960s researchers around the world have started to focus on the elements that could affect one's learning ability and performance, especially on language learning. Cognitive styles, personalities and motivation are the main points that many researchers are focusing on. Cognitive style is the main aspect. One's cognitive style is affected by himself and his surroundings (Allport, 1938). Among all the different classifications, FI/FD styles are the most acknowledged theory. The theory of FI/FD styles is to distinguish those who receive and process information internally from externally. This feature can influence a person in many aspects. Reading holds an important position in language learning, and it's one of the most common ways to test a person's linguistic competence. There are many factors influencing one's reading ability, reader variables, text variables and writer variables. As a reader, the only thing can be changed is reader variables. Reader variables refer to one's mental condition, knowledge reserves and cultural background information. There are intersections between reader variables and reading strategy. Reading strategy is applied while reading, though people may not be aware of it. Reading strategies are the process in which readers are dealing with reading materials with a certain purpose (Barnett, 1988). Also, reading strategy can be related to many other factors, high proficiency learners' meta-cognitive strategy and cognitive strategy are higher than low proficiency learners. But the compensation strategy is the opposite situation (Huang, 2012). There are many researches about cognitive styles and learning performance, such as listening, reading and speaking. Among all the researches at home and abroad, how the FI/FD cognitive styles and reading strategies would affect reading performance is still a hot topic. Helping more learners to achieve a better result is what many researchers are committed to. Reading is the process of cognition, reorganization and construction of information and its complexity often hinders the performance of L2 learners. Being aware of learners' cognitive styles and their personalities can surely help to improve their learning efficiency by customizing their own learning strategies and patterns. 
There are many researches focusing on how cognitive style and reading strategy impact on one's language learning and reading. Reading strategy has been studied for educational use for many years in China. However, there are few studies focusing on specific subjects and put their results into practice. Based on the theory of field cognitive styles and reading strategies, the present study tries to take the freshmen majoring in material engineering at BIPT as the subjects, exploring their tendency in field cognitive style as well as the correlation between their field cognitive styles and English reading strategies. The results are expected to help students know better about their preference in the learning process and achieve more success in second language acquisition.

\section{Literature Review}

\subsection{Cognitive Style}

Cognitive styles are used broadly in many aspects, Allport in 1934 first combined "cognitive" with "style", and it's under cognitive psychology which is the study of the mental process developed in the 1940s and 1950s. Cognitive styles were studied under different names by different authors, such as learning styles, thinking styles or styles of thought. Under the same basic definition of the phrase, "cognitive styles" were carried out differently by different authors. Allport (1934) brought out this theory in his work Personality: A Psychological Interpretation. He used "cognitive style" to expound the various ways people tend to receive information and solve problems. Researchers after him try to clarify this theory, the definition became more detailed. Witkin et al. (1977) advocates that cognitive style is the way individuals perceive, think, solve problems, learn, and relate to others. Messick (1984) defined cognitive styles as an individual difference, how a person organizes and processes information. Many researchers put cognitive style under the category of learning style, but Keefe (1979) point out that learning styles include more than cognitive styles, also include emotion and physiology in. Cognitive styles as a well-known theory, on the basis of the original definition, many researchers have their own point of view. With more researches done, more and more definition came out. The category of cognitive styles is various, since the researchers added more details on their cognitive style theories. There is no official classification for cognitive style yet, among those different classifications, some of them are well-known. Klein in 1954 divides cognitive style into Sharpening style and leveling style. Reflective style and impulsive style were Kagan's theory brought out in 1964. Guilford formed convergent style and divergent style theory. And Witkin's theory, field independent and field dependent, is now the most accepted theory. Many theories after his are not getting more attention.

\subsection{FI/FD Cognitive Style}

Witkin first put forward the theory of field cognitive style in the 1940s. After that more researches have been done by him and his colleagues. They did many researches in many aspects on the basis of their theory. As an early theory, FI/FD theory is received much more attention than others. The following studies of FI/FD cognitive style are extended to many other fields, especially in language study. Witkin's definition of FI/FD cognitive styles is the foundation of all related researches. FD/FI refers to while people receive and deal with information and their interaction with the outward environment, whether they depend on external or internal references; those who preferred to depend on external references and were difficult to distinguish a simple embedded figure from a complex one can be considered as field dependent, those preferred to depend on internal references and were effortless to distinguish a simple embedded figure from a complex one can be considered as field independent(op.cit, 1977).

In his research, he applies FI/FD cognitive styles into education, to find out the same main elements that could impact on one's learning such as sex differences. The two styles are getting some different results, Chen and Xiao (2014) suggest that different FI/FD cognitive style tends to focus on different parts while listening. Some researchers believe in certain field one is better than another. Chapelle (1995) suggests that a field-dependent person would have a better social relationship and sensitivity, and Wang (2014) believes that FD learners are better than FI learners in abstract thinking ability. While Nozari and Siamian (2015), suggest that the FI style leads to better reading skill and more achievement. FD/FI cognitive styles have different characters. Different researchers have their own standard to differentiate between two styles. Some differences can be found in the characteristic of FD/FI styles according to the different researchers. But most of them are similar, from the book, Approaches and Methods in Language Teaching, FI/FD styles were described as follows. People with field-dependent style, their process of receiving and processing information is taking it as a whole, tend to predict more about it, and their attention is focused on meaning. Fieldindependent cognitive style is just on the opposite. From the authors of the book, they believe that highly contextualized interactive communicative experience is the way for FD learners to achieve more success in L2 acquisition, and decontextualized analytic approaches and formal instruction will conduce to FI learners. 


\subsection{Reading Strategy}

Reading is one of the basic ways to get information and part of the process of learning. In many studies, reading strategy is under the learning strategy category. Recent years, people pay much more attention on reading. Reading strategies are very important for students, especially for language learning. In China, most students learn English as their second language. For those students reading Chinese text won't be an issue. But they do use reading strategies. The phrase reading strategy may not be so familiar, but as Flavell (1987) suggests that while people using reading strategy automatically and they are so well practiced that they do not aware of it. The strategy a person uses could be different depending on its English text or Chinese text, since the language backgrounds and experience are different (Parry, 1996).

Reading strategy for a long time belongs to learning strategy, which has been studied by many researchers for about thirty years. In recent years, people have begun to realize the importance of reading strategy, and separated it from the learning strategy. Back at the time when most researchers still did not have the idea to distinguish reading strategy from learning strategy, Block (1986) came up with the theory that reading strategy is conscious and dynamic, which is the process of interaction between reader and content. Block's theory reveals that reading strategy is the way people communicate with the text. Another researcher has a similar definition to it. Barnett (1988) believes that reading strategies are the process in which readers are dealing with reading materials for a certain purpose. So, reading strategies are the skills people use when one takes in information from a text. With different skills, people are labeled with different reading strategies. Reading strategy can be influenced by many factors, for example, sex differences. Huang (2012) suggests that female uses reading strategies more often than male, and with different proficient learners they prefer different strategies. For language learners, reading strategies are useful under some conditions, Yang et al. (2013) point out that without a basic knowledge [vocabulary, grammar...] certain strategies can be used while reading. The classification of reading strategy was borrowed from learning strategy. Researchers in this field didn't figure it out until recently, Anderson's classification of reading strategies is divided into three categories, Cognitive reading strategies, Meta-cognitive reading strategies, Compensating reading strategies (Anderson, 1999). Grabe and Stoller (2002) build a similar one with only two categories, Cognitive reading strategies, Meta-cognitive reading strategies. Another researcher O'Malley also classifies the reading strategies into three. Besides the most common two, he added social/affective strategies, which include a question for clarification cooperation and affection.

In Anderson's classification, compare to Grabe and Stoller's chart, compensating reading strategies classified a kind of person who taking notes, memorizing and reviewing, etc. under it, and the other two are similar at some point. On cognitive reading strategies, both researchers describe it as predicting, distinguish main ideas from facts. However, in O'Malley and Chamot's classification, some of the characteristics are on the contrary. It seems the meta-cognitive reading strategies and cognitive reading strategies are the most accepted categories. There are many researches focusing on how cognitive style and reading strategy impact on one's language learning and reading. Reading strategy has been studied for educational use for many years in China. The field cognitive styles and reading strategies are very important for language learning. Previous studies showed that with different field cognitive style, people tend to apply different reading strategies to get information. This research will focus on the students who are majoring in material engineering at BIPT, which is an applied technological university and most of its disciplines are science and engineering related. The goal is to explore their tendency in field cognitive style as well as the correlation between their field cognitive styles and English reading strategies. Language learners will improve their reading comprehension more convenient and efficient after knowing their preference in the field cognitive styles.

\section{Methodology}

\subsection{Research Questions}

On the ground of the theory of cognition and language learning strategy, the study aims to explore the correlation between the FD/I cognitive styles and reading strategies. The following questions will be answered in this study:

1. What is the general tendency of FI/D cognitive style of freshmen in Beijing Institute of Petrochemical Technology?

2. Do students with different field cognitive styles tend to employ different reading strategies?

\subsection{Participants}

Since the present study is to determine the correlation between field cognitive styles and English reading strategies of students at BIPT, the participants of this study are the freshmen majoring in material engineering at BIPT. They are all students with an English proficiency of level B (the intermediate level based on the Entrance Level Test hosted by BIPT), who have already developed their own particular reading habits in the process of 6 to 8 years of English learning. 
There are 175 participants taking part in the survey, 124 tests and 90 questionnaires are qualified because of the incompletion of information.

\subsection{Instruments}

The instruments used for subject selection and data collection in this study include Group Embedded Figure Test (Chinese version) and the questionnaire of reading strategy. Group Embedded Figure Test (Chinese version), and the questionnaire of reading strategy are designed to learn about the current situation of cognitive styles and English reading strategies, and the ways to improve students reading performance. The questionnaire consists of personal information and questions concerning the students' FI/FD cognitive styles, English reading strategies.

\subsubsection{Group Embedded Figure Test (Chinese version)}

The Group Embedded Figure Test (GEFT) used in the present study is the Chinese version, it was designed to find out the 9 simple graphics provided in the beginning in the complex ones. The test is divided into three parts, the first part is only to familiarize the participants with the question type, the second part and the third part are counted in the results. The total score for the test is 20 . There are three normative score and normative standard deviation as reference.

Using the two formulas as follow:

$\mathrm{t}=($ statistical score - norm score $) /$ norm standard deviation

$\mathrm{T}=\mathrm{t} * 10+50$

If $\mathrm{T} \geq 50$, then the subject tends to be field independent, otherwise the subject tends to be field dependent. The GEFT is shown in Appendix I.

\subsubsection{The questionnaire of reading strategy}

The questionnaire is intended to find the strategies that the participants would usually use to help them to understand English passages. Each individual has a tendency to employ different techniques, after years of study, researchers carried out the theory of reading strategies. The questions are designed to discover the participants' practice in English reading tests. Participants can choose one option that meets his/her condition for each question. The questions are designed based on O'Malley and Chamot's (1990) classification in Chinese. The first part contains the instruction of the questionnaire and the background information of the participants. The second part is about English reading strategies. The questions are classified into 3 group, the first group includes 11 questions about meta-cognitive strategies, $(1,5,9,10,12,13,14,15,17,18,20)$; and the second group is about cognitive strategies, includes 10 questions, $(2,3,4,6,7,8,11,16,19,23)$; and the third part is about social/affection strategies, includes 2 questions, $(21,22)$. For 22 questions are given 5 choices marked A (I never do this); B (I do this occasionally); C (I do this sometimes); D (I usually do this); $\mathrm{E}$ (I always do this). And the score is given as follows: A=1, B=2, C=3, D=4, E=5. For the 10th question, it is different. For this question, there are only 3 choices, and it is intended to choose the decision that students made while meeting a new word. The score for the choices is: $\mathrm{A}=1 ; \mathrm{B}=2 ; \mathrm{C}=3$. The final score for each group is: meta-cognitive strategies are (11-53), cognitive strategies are (10-50), and social/affection strategies are (210). The questionnaire is shown in Appendix II.

\subsection{Data collection and analysis}

The questionnaire and test employed in this study are carried out in March 2019. The questionnaire was designed on https://www.wjx.cn/ and the test is from the website. WeChat is employed to send out the questionnaire. The Group Embedded Figure Test is printed out for the participants, and they are required to finish the test in class. The participants will be selected randomly. The data will be collected to analyze students' FI/FD cognitive styles and English reading strategies they applied while reading. The results of the questionnaire will be downloaded from the internet in the Excel version. The test paper will be collected after the participants finished it. For ensuring the validity of the data, it will be tested in SPSS (IBM SPSS Statistics 24). The basic information will be provided to the participants before the questionnaire is conducted. The questionnaire is for research use only, and will not expose any information about the participants. The Group Embedded Figure Test will be carried out according to the requirements. The score of the test will be input in the Excel for further calculations. To avoiding calculation mistakes, the formulas will be input into the Excel, to get the final results. Both of the GEFT and the questionnaire are included personal information. Then the results of the test will be associated with the questionnaire according to the information. And 90 participants are chosen randomly from the results to analyze the second research question. Independent-Samples T Test in the SPSS is to test if there is a significant difference in English reading strategies between the FD/FI students or not.

\section{Findings and Discussion}

The data collected through the questionnaire and test shows that there is a certain tendency of field cognitive styles among freshmen majoring in material engineering at BIPT. 
But the difference in using reading strategies between students with FD/FI cognitive styles is not as significant as that is found out in previous studies. In this chapter, the two questions brought out in this study will be discussed.

\subsection{Result of Group Embedded Figure Test}

Through the SPSS 24.0, the descriptive statistics are conducted to analyze the scores of Group Embedded Figure Test. Table 4.1 shows the mean, median, standard deviation, range, minimum and maximum of the participants. There are 133 valid samples collected from the test. The maximum score is the full score, and the minimum is 7 . The range is considerably large. Depending on the instruction of the test, 99 of the participants are regarded as field independent students and 14 of them are field dependent students.

Table 4.1 the Descriptive Statistics for CSFT of All Participants

\begin{tabular}{lll}
\hline $\mathrm{N}$ & Valid & 113 \\
\cline { 2 - 3 } & Missing & 0 \\
\hline Mean & 14.08 \\
\hline Median & 15.00 \\
\hline Std. Deviation & 3.249 \\
\hline Range & 13 \\
\hline Minimum & 7 \\
\hline Maximum & 20 \\
\hline
\end{tabular}

From Table 4.2, it can be found out that most of the participants tend to be in the FI cognitive style. The results show that the ratio of FI group to FD group is about 7 to 1 . The huge gap between these two groups is not very common, and the mean of FI participants is close to 10. Which indicates most students that the general tendency of FI/FD cognitive style of freshmen in BIPT is field-independent cognitive style. From Figure 4.1, we can see that most of the students got a relatively high score, 15 and 16 are the score most students got.

Table 4.2 the Descriptive Statistics for FD/I Participants' CSFT score

\begin{tabular}{llllllll}
\hline Types & $\mathrm{N}$ & Mean & Median & Std. Deviation & Range & Minimum & Maximum \\
\hline FI & 99 & 14.87 & 15 & 2.629 & 10 & 10 & 20 \\
\hline FD & 14 & 8.5 & 9 & 0.76 & 2 & 7 & 9 \\
\hline
\end{tabular}

Figure 4.1 Number of Students Per Score

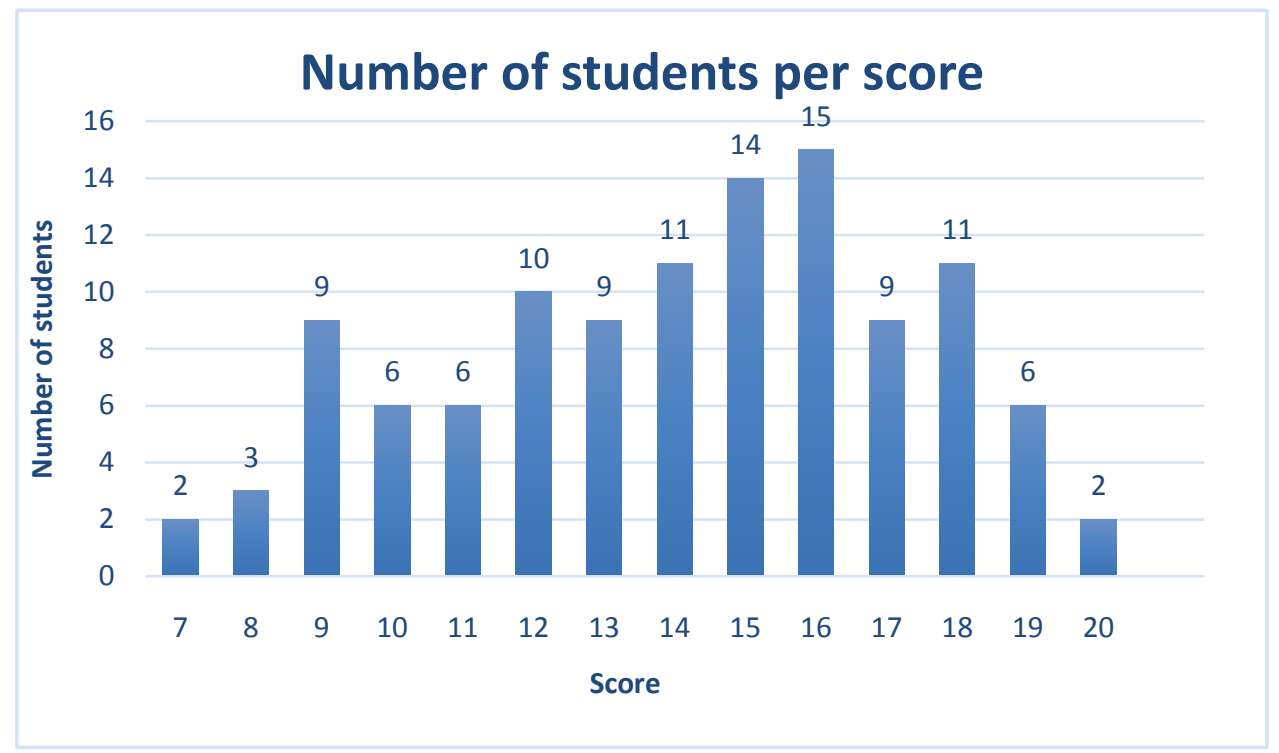

\subsection{Result of the questionnaire}

Table 4.3 shows that the English reading strategies questionnaire is reliable to be used in the current study with Cronbach's Alpha being .843. 
Table 4.3 the Reliability Statistics for Questionnaire of English Reading Strategies

\begin{tabular}{|l|l|}
\hline Cronbach's Alpha & N of Items \\
\hline 843 & 23 \\
\hline
\end{tabular}

Participants are assorted into two groups, FD and FI, according to the result of Group Embedded Figure Test. The independent sample T-test is used to examine if there is a significant difference between the two groups in employing reading strategies.

According to Table 4.4, the mean of the two groups on meta-cognitive strategies and cognitive strategies is very close. It seems that there is no significant difference between two groups of these two strategies. Although the difference in social/affective strategies is more noticeable between FD/FI students, the differences are significant or not is listed in Table 4.5. From the results of Table 4.5, it indicates that there is no significant difference between FD/FI students in all of the three reading strategies. Students with different field cognitive styles are very similar in choosing reading strategies. But the difference between FD and FI is still existing. From Table 4.4, the mean of social/affective strategies for each question is larger than the other two. It reveals that the major difference between FD and FI learners, in this case, is shown in social/affective strategies.

Table 4.4 Descriptive Statistics of English Reading Strategies

\begin{tabular}{|l|l|l|l|l|l|}
\hline \multicolumn{6}{|l}{ Group Statistics Strategies } \\
\hline & FD/I & N & Mean & Std. Deviation & Std. Error Mean \\
\hline Meta-Cognitive Strategies & FI & 79 & 3.052934 & 0.5145906 & 0.057896 \\
\cline { 2 - 6 } & FD & 11 & 3.214876 & 0.6866769 & 0.2070409 \\
\hline Cognitive Strategies & FI & 79 & 2.836709 & 0.5332958 & 0.0600005 \\
\cline { 2 - 6 } & FD & 11 & 2.9 & 0.8342661 & 0.2515407 \\
\hline Social/Affective Strategies & FI & 79 & 2.627 & 0.8491 & 0.0955 \\
\cline { 2 - 6 } & FD & 11 & 3 & 0.8944 & 0.2697 \\
\hline
\end{tabular}

Table 4.5 the Difference between FD and FI Students' English Reading Strategies

\begin{tabular}{|c|c|c|c|c|c|c|c|c|c|c|}
\hline \multicolumn{11}{|c|}{ Independent Samples Test } \\
\hline & & \multicolumn{2}{|c|}{$\begin{array}{l}\text { Levene's Test for } \\
\text { Equality of } \\
\text { Variances }\end{array}$} & \multicolumn{3}{|c|}{$\begin{array}{l}\text { t-test for Equality of } \\
\text { Means }\end{array}$} & \multirow{3}{*}{$\begin{array}{l}\text { Mean } \\
\text { Differen } \\
\text { ce }\end{array}$} & \multirow{3}{*}{$\begin{array}{l}\text { Std. Error } \\
\text { Difference }\end{array}$} & & \\
\hline & & $\mathrm{F}$ & Sig. & $\mathrm{t}$ & df & $\begin{array}{l}\text { Sig. } \\
(2- \\
\text { tailed })\end{array}$ & & & \multicolumn{2}{|c|}{$\begin{array}{l}95 \% \text { Confidence } \\
\text { Interval of the } \\
\text { Difference }\end{array}$} \\
\hline & & & & & & & & & Lower & Upper \\
\hline \multirow[t]{2}{*}{$\begin{array}{l}\text { Meta- } \\
\text { Cognitive } \\
\text { Strategies } \\
\end{array}$} & $\begin{array}{l}\text { Equal } \\
\text { variances } \\
\text { assumed }\end{array}$ & 0.723 & 0.398 & $\begin{array}{l}- \\
0.937\end{array}$ & 88 & 0.351 & $\begin{array}{l}- \\
0.16194\end{array}$ & 0.172794 & -0.50533 & 0.181451 \\
\hline & \multicolumn{3}{|c|}{ Equal variances not assumed } & $\begin{array}{l}- \\
0.753\end{array}$ & $\begin{array}{l}11 . \\
61 \\
6\end{array}$ & 0.466 & $\begin{array}{l}- \\
0.16194\end{array}$ & 0.214983 & -0.63207 & 0.30819 \\
\hline \multirow[t]{2}{*}{$\begin{array}{l}\text { Cognitive } \\
\text { Strategies }\end{array}$} & $\begin{array}{l}\text { Equal } \\
\text { variances } \\
\text { assumed }\end{array}$ & 1.526 & 0.22 & $\begin{array}{l}- \\
0.342\end{array}$ & 88 & 0.733 & $\begin{array}{l}- \\
0.06329\end{array}$ & 0.1852 & -0.43134 & 0.304755 \\
\hline & \multicolumn{3}{|c|}{ Equal variances not assumed } & $\begin{array}{l}- \\
0.245\end{array}$ & $\begin{array}{l}11 . \\
16 \\
6\end{array}$ & 0.811 & $\begin{array}{l}- \\
0.06329\end{array}$ & 0.258598 & -0.63143 & 0.50485 \\
\hline \multirow[t]{2}{*}{$\begin{array}{l}\text { Social/Affect } \\
\text { ive Strategies }\end{array}$} & $\begin{array}{l}\text { Equal } \\
\text { variances } \\
\text { assumed } \\
\end{array}$ & 0.123 & 0.726 & $\overline{-}-3.358$ & 88 & 0.178 & -0.3734 & 0.2749 & -0.9198 & 0.173 \\
\hline & \multicolumn{3}{|c|}{ Equal variances not assumed } & $-\overline{1.305}$ & $\begin{array}{l}12 . \\
64 \\
2\end{array}$ & 0.215 & -0.3734 & 0.2861 & -0.9933 & 0.2464 \\
\hline \multirow[t]{2}{*}{ Total } & $\begin{array}{l}\text { Equal } \\
\text { variances } \\
\text { assumed } \\
\end{array}$ & 1.707 & 0.195 & $\begin{array}{l}- \\
0.865\end{array}$ & 88 & 0.39 & $\begin{array}{l}- \\
0.13744\end{array}$ & 0.15893 & -0.45328 & 0.1784 \\
\hline & \multicolumn{3}{|c|}{ Equal variances not assumed } & $\begin{array}{l}- \\
0.639\end{array}$ & $\begin{array}{l}11 . \\
27 \\
7\end{array}$ & 0.535 & $\begin{array}{l}- \\
0.13744\end{array}$ & 0.21501 & -0.60925 & 0.33438 \\
\hline
\end{tabular}


In this research, participants are classified into FD and FI learners according to the GEFT. Table 4.6 shows the descriptive statistics for FI/FD learners in applying meta-cognitive reading strategies. This table is based on the mean of the total score.

Table 4.6 Descriptive Statistics for FI/FD learners on Meta-Cognitive Strategies

\begin{tabular}{|l|l|l|l|l|l|}
\hline & $\mathrm{N}$ & Minimum & Maximum & Mean & Std. Deviation \\
\hline FD & 11 & 19 & 43 & 35.36 & 7.553 \\
\hline FI & 79 & 21 & 48 & 33.58 & 5.66 \\
\hline
\end{tabular}

From table 4.6, we can see that the mean of FD learners is 35.36, and the mean of the FI learners is 33.58 , these two figures are close. But still, there is a difference between these two groups of students. FD leaners got higher scores than FI learners, as Carter (1988) and $\mathrm{Li}$ (2014) suggested that FD learners may use meta-cognitive reading strategies more frequently. Considering that the present study is mainly focusing on the students majoring in science and engineering, it can be concluded that non-English major students in this specific environment follow the theory that FD learners are likely to apply meta-cognitive strategies, but the difference between FD and FI are very small. Table 4.7 and Table 4.8 show the descriptive statistics for FI/FD learners on cognitive strategies and social/affective strategies. These tables are also based on the mean of the total score.

Table 4.7 Descriptive Statistics for FI/FD learners on Cognitive Strategies

\begin{tabular}{|l|l|l|l|l|l|}
\hline & N & Minimum & Maximum & Mean & Std. Deviation \\
\hline FD & 11 & 14 & 43 & 29 & 8.343 \\
\hline FI & 79 & 17 & 44 & 28.37 & 5.333 \\
\hline
\end{tabular}

Table 4.8 Descriptive Statistics for FI/FD learners on Social/Affective Strategies

\begin{tabular}{|l|l|l|l|l|l|}
\hline & $\mathrm{N}$ & Minimum & Maximum & Mean & Std. Deviation \\
\hline FD & 11 & 3 & 8 & 6 & 1.789 \\
\hline FI & 79 & 2 & 10 & 5.25 & 1.698 \\
\hline
\end{tabular}

The mean of FD/FI is also very close in both Cognitive Strategies and social/affective strategies, and the difference of them is both less than one. Though the difference is not significant, the result shows that FD is superior in both of these two strategies. It matches the theory and findings from previous studies.

From Table 4.6, 4.7 and, 4.8, the result shows that FD learners are better than FI learners in reading strategies employment.

\subsection{Summary and discussion}

The result indicates that the general tendency of the freshmen in the Beijing Institute of Petrochemical Technology is field-independent cognitive style. The ratio of the FI cognitive style to FD cognitive style is nearly 7 to 1 . There are factors that led to this result. The test is designed to find out the ability to pick out simple graphics from the complex ones, and this ability can be improved by training. Most of the students majoring in material engineering are good at math and geometry, so it is effortless for them to perform better on the test. In other words, it would be easier for students to finish this test since they have learned geometry for years. It explained why the students got a very high score in the test. It also reveals that most students studying in science and engineering have strong ability in abstract thinking, and they are FI learners, as Wang suggested (2014). The result of this study does not conform to that of previous studies. Based on the data analysis, there are no significant differences between FD and FI students. But the feature of FD and FI learners does not change. This unusual result may be the feature appears in science and engineering colleges or universities. There are factors that could change the reading strategies they employ while reading. Besides, students are working to improve their reading performance by asking for advice from teachers or classmates who are good at reading comprehension. Therefore, in a different environment, students' reading strategies can be changed by it. The difference between FD/FI learners in applying reading strategies is not significant, but the difference corresponds to the theory that FD is superior to using reading strategies.

\section{Major findings}

For language learners, the cognitive style is definitely an important factor that can affect their learning results. Therefore, it is essential for them to be aware of their own preference in thinking and learning, which helps them step on the right track to achieve academic success. Reading, as the most complicated activity of information processing, is always regarded as one of the most common ways to test one's language proficiency. This study aims to explore the tendency of the cognitive styles of freshmen in the material engineering major and the correlation between FD/I 
cognitive styles and the reading strategies. The findings are as follows. First, there exists a certain tendency of field cognitive styles among freshmen majoring in material engineering at BIPT. A vast majority of them (up to 88 percent) tend to be field independent. Second, in this specific case, the field cognitive style does not have a significant correlation with the employment of English reading strategies. The result is different compared with previous studies. The participants are the major influencing factor, and it's also the main reason to design this research. It is noted that FD learners tend to use meta-cognitive reading strategies more frequently and also FD learners are better at social/affective strategies. In addition, the result indicates that the students with FD cognitive style tend to practice on the passages they have done repeatedly.

\section{Implication of the study}

The field cognitive styles and reading strategies are very important for language learning. Being aware of their preference in the field cognitive styles, language learners can be more convenient and efficient to improve their reading comprehension. From the perspective of teachers, design more group works for FD learners is a smart choice, because discussing and solving problems together as a group are the best ways to improve their performance. Conversely, for FI learners, working together would slow them down. It would be better if they work on their own, which would help them to think better. As FD students, the way to improve language learning is to work with others and ask for help if there are questions need to be solved. As FI students, working as an individual is the most efficient way.

\section{References}

Allport, G. W. 1938. Personality: A psychological interpretation [J]. American Journal of Sociology, (1): 48-50.

Anderson, N. J. 1999. Exploring Second Language Reading: Issues and Strategies [M]. Boston: Hauula \& Heiule Baker, L. \& Brown A.L.

Barnett, M. 1988. Reading through Context: How Real and Perceived Strategy Affects Second Language Comprehension [J]. Modern Language Journal 6(11): 150-162.

Carter, E. F. 1988. "The Relationship of Field Dependent \& Independent Cognitive Style to Spanish Language Achievement and Proficiency: A Preliminary Report" [J]. Modern Language Journal, (72): 21-30.

Chapelle, C. 1988. Field Independence: A Source of Language Test Variance [J]. Language Testing 5: 62-82.

Flavell, J. H., 1987. Speculations about the nature and development of metacognition [A]. In F.E. Weinert \& R. H. Kluwe (eds.). Metacognition, motivation, and understanding [C]. Hillside, New Jersey: Lawrence Erlbaum Associates Publishers. 1: 21-29.

Grabe, W. \& Stroller, F. L. 2005. Teaching and Researching Reading [M]. Beijing: Foreign Language Teaching and Research Press.

Keefe, J.W. 1979. Student Learning Styles: Diagnosing and Prescribing Programs [M]. Reston, VA: National Association of Secondary School Principals.

Messic, S. 1984. The Nature of Cognitives: Problems and Promisex in Educational Practice [J]. Educational Psychologist 19: 59-74.

Nozari, A. Y. \& H. Siamian. 2015. The Relationship between Field Dependent-Independent Cognitive Style and Understanding of English Text Reading and Academic Success [J]. Mater Sociomed 27(1): 39-41.

O’Malley, M. \& C. Anna. 1990. Learning Strategies in Second Language Acquisition [M]. New York: Cambridge University Press.

Parry, K. 1996. Culture, Literacy, and L2 Reading [J]. TESOL Quarterly 30(4): 665-692.

Richards, J. C. \& T. S. Rodgers. 2008. Approaches and Methods in Language Teaching [M]. Beijing: Foreign Language Teaching and Research Press, Cambridge University Press.

Sabet, M.K. 2013. The Relationship between Field Independence/ Dependence Styles and Reading Comprehension Abilities of EFL Readers [J]. Theory and Practice in Language Studies 3(11): 2141-2150.

Witkin, H. A., Moore, C. A., Goodenough, D. R., \& Cox, P. W. 1977. Field-dependent and field-independent cognitive styles and their educational implications [J]. Review of Educational Research 1: 1-64. 